\title{
Integrating Teaming, Writing, and Speaking in CHE Unit Operations Lab
}

Dave Kmiec, Chris M. Anson, Paula Berardinelli, Lisa Bullard, Deanna P. Dannels, Naomi Kleid, Steven Peretti, James J. Spivey

North Carolina State University 


\title{
Integrating Teaming, Writing, and Speaking in CHE Unit Operations Lab
}

\author{
Dave Kmiec, Chris M. Anson, Paula Berardinelli, Lisa Bullard, \\ Deanna P. Dannels, Naomi Kleid, Steven Peretti, James J. Spivey \\ North Carolina State University
}

\section{Rationale}

With the recent evidence for industrial demand ${ }^{[1]}$ and the advent of communication-focused ABET requirements, ${ }^{[2]}$ engineering programs across the nation are trying to find ways to integrate disciplinespecific and multidisciplinary technical communication into their curricula. A review of the literature suggests that the majority of this integration has been in the form of genre-model writing classes for the freshman and sophomore level ${ }^{[3]}$ and portfolio-based additions to capstone courses at the senior level.

For the past two years, a research and teaching team in the chemical engineering department at North Carolina State University has been iteratively designing and implementing a junior-level writing and speaking module as part of a larger NSF grant. ${ }^{[4]}$ The purpose of this module is to provide instruction in technical writing, oral presentation, teaming, and project management skills within the context of the laboratory course. This serves as a precursor to a similar senior capstone course that includes instruction in multidisciplinary teaming.

\section{Design features}

The Teaming, Writing, and Speaking (TWS) instruction series is a discipline-specific module and consultation series that was designed to complement a junior-level chemical engineering laboratory survey course in chemical engineering (CHE 330). The students in 330 meet one morning a week for hour-long lectures on statistics and experimental design. In addition they have one three-hour afternoon period reserved every week for experiments. Students who enroll in the course attend four TWS modules, which take place during their allotted lab time on weeks when there is no experiment scheduled. They also meet as a team with writing and speaking consultant four times throughout the semester. Table 1 shows a typical schedule for students' activity in TWS and in the lab.

The TWS module focuses on developing collaborative oral and written technical communication skills by addressing how members of teams prepare oral and written laboratory reports and identify and resolve issues related to writing, speaking, and interpersonal interaction (Table 2).

Using in-class activities and discussions, the module applies topics in technical and small-group communication to real engineering teams and projects within the context of the course. Students are encouraged to develop a casual and productive inter- and intra-group rapport and are frequently asked to work in teams to discuss situations or perform tasks and then share their findings with the class. The instructor has structured activities and prepared lecture material to facilitate the instruction. 
Table 1: CHE 330 Course Calendar

\begin{tabular}{l|lll}
\hline Week & Module topic & Lab activity & Consultation topic \\
\hline 1 & Teaming (introduction) & & \\
\hline 2 & & Conduct experiment \#1 & \\
\hline 3 & & Lab report \#1 due & \\
\hline 4 & Collaborative writing & Conduct experiment \#2 & \\
\hline 5 & & & Report Organization \\
\hline 6 & & Lab report \#2 due & \\
\hline 7 & Teaming & Conduct experiment \#3 & \\
\hline 8 & & Report \#3 due & Graphics and layout \\
\hline 9 & & Conduct experiment \#4 & \\
\hline 10 & Collaborative speaking & & Rehearse oral presentation \\
\hline 11 & & Oral presentation & \\
\hline 13 & & &
\end{tabular}

The individual team consultations, on the other hand, are unscripted - although they frequently explore themes like graphics communication, mechanics, or academic integrity. The primary focus of these sessions, however, is to allow students to bring the consultant a work-in-progress for discussion in a workshop setting.

The consultation sessions emphasize the importance of developing and implementing a systematic writing and editing process. Often the consultant facilitates the integration of the collaborative writing, presenting, and editing skills that students were exposed to in the module by helping them apply these skills to creating the reports and presentations required by the laboratory portion of the course.

For the final consultation of the semester, several teams of students meet during the common module time and rehearse their presentations in a critical speaking environment where they can participate in the evaluation process and respond to real questions and answers from their peers. This opportunity to practice before a critical audience, like the one they will have on their presentation day, gives the students realistic speaking practice.

Table 2: TWS Proficiencies and Corresponding Skills
Proficiency
Corresponding skills
Collaborative technical writing
- write collaboratively
- function as a peer editor

Collaborative technical presentation

- convey technical material orally in a way appropriate to the audience

- work collaboratively to design and conduct a technical presentation

Teaming

- identify and fulfill team roles

- create, use, and revise team ground rules

- recognize and manage conflict in teams

- recognize and manage decision making in teams

- provide frequent and productive feedback to team members regarding teaming, writing, and speaking skills

The most novel aspect of this course is its unique integration with a preexisting junior-level laboratory survey course, which allows students to find immediate application for the concepts presented in the modules and consultations. Typically, as students apply the writing, editing, and management techniques, 
their lab reports become more refined and the writing component of their grade on those reports improves. This proof of concept, in combination with a few directed assignments (Table 3), encourages students to internalize the processes and find ways to apply them in future lab writing settings.

Table 3: Assignments and Corresponding Proficiencies for Both CHE 330 and TWS

\begin{tabular}{|c|c|c|}
\hline Assignment & Course & Proficiency \\
\hline 3 written lab reports & CHE lab course & technical; writing \\
\hline Written executive summary & CHE lab course & technical; writing \\
\hline Oral presentation & CHE lab course & technical; presentation \\
\hline $\begin{array}{l}\text { Informal written report } \\
\text { (on how writing standards vary by context) }\end{array}$ & TWS module & writing \\
\hline Project management organizational chart & TWS module & teaming \\
\hline $\begin{array}{l}\text { Process notebook } \\
\text { (includes agendas, minutes, and reflections) }\end{array}$ & TWS module & teaming \\
\hline
\end{tabular}

The transferability of teaming, writing, and speaking instruction to other universities was also considered when designing TWS. The module format employs interchangeable, independent discussions and exercises that can be assembled in a variety of combinations. Likewise, the consultation format allows for flexible scheduling and targeted, personalized team attention. The two formats can be used alone or in combination. This allows an instructor to devote as much time and as many resources as possible.

\section{Assessment}

TWS, in its fourth iteration, has evolved from a basic-concepts lecture series to the module and consultation series described above. In Spring 2003, approximately half ${ }^{[5]}$ of the CHE 330 students will attend TWS modules and consultations. The other half will receive only the standard advice on preparing reports and presentations that has traditionally accompanied the laboratory lecture. ${ }^{[6]}$ Using the metrics listed below (see Table 4), we will be able to compare the subject group and the control group and quantify the effect of the TWS training on our students' performance and attitudes.

Table 4: Spring 2003 Experimental Metrics

Metric

Pre-and post-course self-report (survey)

Comparative analysis of oral presentation

Comparative analysis of written lab assignments

Teaming skills assessment rubric, completed by the instructor and the consultant

\section{Corresponding proficiency}

teaming; writing; speaking

speaking

writing

teaming

\section{Conclusion}

Proceedings of the 2003 American Society for Engineering Education Annual Conference \& Exposition Copyright (C) 2003, American Society for Engineering Education 
Since appearing in the ABET required competencies several years ago, fragments of teaming, writing, and speaking education have been distributed, sometimes haphazardly, across the core courses in engineering departments nationwide. Searching for an alternative method of integrating these new competencies, a team of researchers at North Carolina State University has constructed a junior-level discipline-specific teaming, writing, and speaking (TWS) module and consultation series. Material for this program is available on the web: http://www2.ncsu.edu/unity/lockers/project/actionagenda/index.html. Assessment data, which will be available in the summer of 2003, will suggest the impact of presenting this material in this format as opposed to less structured methods.

Lang, J.D., S. Cruse, F.D. McVey, and J. McMasters. "Industry expectations of new engineers: A survey to assist curriculum designers." Journal of Engineering Education 88.1 (1999): 43-51.

${ }^{2}$ Accreditation Board for Engineering and Technology. ABET Home. http://www.abet.org. 2002.

${ }^{3}$ There are numerous examples of this type of course in the literature. One example is:

Walker, Kristin. "Using genre theory to teach students engineering lab report writing: A collaborative approach." IEEE Transactions on Professional Communication 42.1 (March 1999): 12-19.

${ }^{4}$ The text of this article is derived from larger findings of NSF Grant \#EEC-0080484 "Establishing New

Multidisciplinary Curricular Paradigms: Biotechnology and Chemical Engineering." Acknowledgment for these findings should be given to the authors of this article and to Amanda Granrud, Coordinator of Undergraduate Tutorial Services in Writing and Speaking at NC State.

${ }^{5}$ The typical spring enrollment for CHE 330 is approximately 75 students.

${ }^{6}$ A number of methods were considered for dividing the class into TWS and non-TWS groups. Logistically, however, the use of the common lab time on non-lab weeks led to the following selection method for Spring 2003: students who enrolled in Monday, Tuesday, or Wednesday sections of the lab were assigned to TWS, while students enrolling in Thursday or Friday lab sections received the more traditional instruction. To prevent students from intentionally enrolling in or avoiding the module, students were not notified of this during registration.

\section{CHRIS M. ANSON}

Chris M. Anson received his Ph.D. from Indiana University and is Professor of English and Director of the Campus Writing and Speaking Program at North Carolina State University, where he teaches graduate and undergraduate courses in language, composition, and literacy and works with faculty in nine colleges to reform undergraduate education in the areas of writing and speaking. He has published widely.

\section{PAULA BERARDINELLI}

Paula Berardinelli received her Doctorate of Education in Training and Development from North Carolina State University and a Master's in Health Education and a Bachelor's in Health Planning and Administration, both from The Pennsylvania State University. She is currently an Assistant Professor of the Training and Development Program at North Carolina State University and has worked as a consultant in a variety of industries.

\section{LISA BULLARD}

Lisa G. Bullard received her BS in ChE from NC State and her Ph.D. in ChE from Carnegie Mellon. She served in engineering and management positions within Eastman Chemical Co. from 1991-2000. At N.C. State, she is currently the Director of Undergraduate Studies in Chemical Engineering.

\section{DEANNA P. DANNELS}

Deanna P. Dannels received her Ph.D. in Communication from the University of Utah and is currently an Assistant Professor in the Department of Communication and the Assistant Director of the Campus Writing and Speaking Program at North Carolina State University. She teaches courses on instructional theory and research methods and 
her research focuses on learning communication in technical disciplines, with a specific emphasis on engineering.

\section{NAOMI KLEID}

Naomi Kleid has a Ph.D. from Rensselaer Polytechnic Institute, specializing in Research Methods and Communication Within a Computing Environment. She has extensive industry experience at headquarters levels setting communication strategy and in research and development leading cross-functional teams and serving in project management positions.

\section{DAVE KMIEC}

David Kmiec has an undergraduate degree in Chemistry and English from University of North Carolina at Wilmington and is currently pursuing his MS in Technical Communication at North Carolina State University. He has worked in writing and speaking centers at both universities and is currently a technical consultant and trainer for Scriptorium Publishing in Research Triangle Park, NC.

\section{STEVEN W. PERETTI}

Steven W. Peretti is an Associate Professor of Chemical Engineering at North Carolina State University. A recipient of the NSF Presidential Young Investigator Award in 1991, he has directed research in bacterial protein synthesis, bioremediation, gene transfer in biofilms, and green chemistry applications of bioconversion processes. Recently, he has become active in the areas of cross-disciplinary education and service learning.

\section{JAMES J. SPIVEY}

James J. Spivey is the Shrivers Professor of Chemical Engineering at Louisiana State University. He was Senior Program Director at Research Triangle Institute and Research Professor at NC State prior to joining LSU in Jan 2003. He worked with colleagues at NC State to enhance the teaming and technical communication skills of students in the undergraduate engineering curriculum. 